\title{
Examination of Corporate Social Reporting and Financial Performance
}

\author{
Cesar Castellanos \\ Walden University \\ Minneapolis MN, USA
}

\author{
Ify S. Diala-Nettles \\ Contributing Faculty \\ Walden University \\ Minneapolis MN, USA
}

\begin{abstract}
Organizational leaders around the world spend millions of dollars on ineffective corporate social responsibility (CSR) programs and CSR reporting strategies. Understanding the relationship between CSR reporting, CSR indices (CSRi), and financial performance is necessary to minimize unnecessary expenditures among organizational leaders. The purpose of this quantitative correlational study, grounded in Frederick's CSR theory and Freeman's stakeholder theory, was to examine the relationship between CSR reporting, CSRi, and financial performance of hardware and software organizations. Data were collected from the Security Exchange Commission and the official websites of 25 hardware and software organizations that were part of Fortune 500 between the years 2010-2015. The results of the multiple linear regression indicated that there was no statistically significant relationship between CSR reporting, CSRi, and net income. Similarly, no significant relationship existed between CSR reporting, CSRi, and return on assets. The implications for social change include the development of socially responsible strategies that take into consideration the ethical variables of dignity and respect and the uncertainties faced by individuals within the community.
\end{abstract}

Keywords: Corporate social responsibility (CSR); CSR reporting; CSR indices (CSRi); Financial performance; Sustainability; Stakeholders.

\section{INTRODUCTION}

Corporate social responsibility (CSR) is a topic of constant debate among scholars and business practitioners. Numerous researchers and practitioners advocate the view that CSR strategies encompass the efforts conducted by organizational leaders to achieve social stability. Frynas and Yamahaki (2016) pointed out that throughout history, CSR strategies were perceived as crisis handling mechanisms. Marples (2017) advocated the view that during a crisis management process, organizational leaders try to report their crisismitigating approaches, hoping to safeguard the already questioned ethical standpoint. CSR reporting strategies are to be used as planning mechanisms and should be included in today's complex business models. To account for the holistic view that governs our value-maximization business culture, it was necessary to employ a quantitative correlational model to confirm or deny the level of relationship between CSR reporting, CSRi, and financial performance. Understanding that CSR involvement may decrease information irregularities and potential debts associated with non-socially accepted activities (Svantesson, Silén, \& James, 2017), it was essential to indulge the income-driven business population by examining accounting-based measures such as net income (NI) and return on assets (ROA) as the dependent variables. The sample's annual reports filed to the Security Exchange Commission (SEC) between the years 2010-2015 and the sample's CSR indices (as provided by the Reputation Institute), served as critical components of the data gathering process. To facilitate the future reproduction of this study, a relatively easy data analysis model was employed to assess the level of relationship between the variables. If duplicated in the future, the applied statistical model can facilitate the scrutiny process of organizational leaders interested in understanding the implications of adequately reporting CSR actions. As mentioned by CSR researchers such as Agudo, Garcés, and Salvador (2015), engaging in socially responsible activities can translate to positive economic performances.

\section{PROBLEM \& PURPOSE OF THE STUDY}

Adverse profitability in the U.S. technology industry is associated with organizational leaders' inability to accurately report their corporate social responsibility strategies (Michelon, Pilonato, \& Ricceri, 2015). During the years 2010$2015,42 \%$ of hardware and software organizations listed in the United States experienced a change in their financial performance after employing or modifying their CSR reporting strategies. The general business problem was that various organizational leaders in the U.S technology industry do not use the proper CSR reporting tools to address stakeholders, resulting in a negative variation in their financial performance. The specific business problem was that limited reliable information is available for U.S. executives and business owners of small- and medium-sized hardware and software organizations in the United States to understand the relationship between CSR reporting, CSRi, and financial performance. The purpose of this quantitative correlational study was to examine the relationship between CSR reporting, $\mathrm{CSRi}$, and financial performance. The independent variables were CSR reporting, obtained by coding the sample's annual reports to the SEC, and CSRi, as provided by the Reputation Institute. The dependent variables were NI and ROA. The targeted population was comprised of executives and business owners of small- and medium-sized software and hardware manufacturing organizations in the metropolitan area of Austin, Texas. This population was suitable for this study because $99 \%$ of software and hardware organizations in the United States are led by small- and medium-sized organizational leaders that do not understand the relationship between CSR reporting and financial performance. The implications for notable social change include the development of socially responsible strategies that take into consideration the ethical variables of dignity and respect, and the uncertainties faced by individuals in their communities. 


\section{DISCUSSIONS}

\subsection{Background of CSR} CSR-1: 1930s to the 1970s

Scholars such as Babiak and Kihl (2018) argued that the notion of business responsibility emerged in the 20th century with the rise of an idea referred to as socially oriented business leaders. The conglomeration of historical events such as (a) World War I, (b) the rise of notorious dictatorships, (c) human rights movements, and (d) the United States' depression, marked the inauguration of the CSR concept. CSR supporters such as Fontana (2018) concurred that through history, business leaders had maintained an ambiguous understanding of business responsibility, but the concept of business social responsibility can be traced to 1937 . To clarify the concept of business responsibility. To ease the understanding of CSR's complex evolutionary process, Frynas and Yamahaki (2016) cited an article published in the 1940s. Frynas and Yamahaki referenced this article to explain how the population of the 1940s viewed the concept of CSR. This article was published in a business magazine of the era, and it is constantly cited as the first scholarly attempt to confirm or deny a relationship between business responsibility and customer acceptance. Frynas and Yamahaki pointed out that the results showed in this article demonstrated that costumers of the epoch were willing to consume more from organizations that made an effort to improve their communities. Though Brown and William (2013) tried to determine the roots of the CSR theory by referencing topics such as organizational ethics and social responsibility, without a doubt, Frederick's $(1978,1986)$ work has been identified as the theoretical framework of the CSR field. Frederick (1978) argued that the history of CSR could be segmented into three notable evolutionary stages. Frederick determined that researchers belonging to the CSR-1 evolutionary stage started to address the notion that business leaders needed to consider the necessities of their communities and that there was a need for business professionals to develop business models that included strategical approaches tailored to the needs of their societies. Frederick observed that the CSR-1 period was filled with immense economic turmoil, not only because of the economic effects brought by the great depression of 1930 but also because of the involvement of the United States in World War II. Other scholars such as Abernathy, Stefaniak, Wilkins, and Olson (2017) and Frynas and Yamahaki (2016) comprehended that CSR's evolutionary process stopped as a reaction to the great depression of 1930; however, Frederick realized that the numerous social movements introduced by the post-World War II period offered a new way of associating businesses and societies. Frynas and Yamahaki explained that the first attempt to theorize CSR emerged from a new group of researchers schooled during and after World War II. The new wave of business leaders and scholars promoted the need for enhanced business management schooling and the establishment of employee-oriented human resource departments (see Brown \& Zmora, 2015). Brown and Zmora indicated that scholars of the CSR-1 era began to discuss the benefits of becoming socially accepted organizational leaders. Frederick (1986) pointed out that business leaders of the postwar era understood the concept of social responsibility; however, a significant percentage of business leaders needed to understand factors such as:

- Businesses and their impact on the well-being of the citizens comprising their communities.
- The importance of not exploiting natural and human resources.

The rise of a more educated and conscious society.
The introduction of women to the workforce.
- The relationship between being a socially
responsible organization and customer perception.

Researchers and practitioners of the CSR-1 period tended to define CSR as:

- Socially oriented organizational actions that range outside of the scope of standard business transactions.

- An organization's moral obligation towards society.

- The ethical and moral obligation of attending environmental issues, enhance the workforce, and meet social needs.

- The ability to allocate funds towards social and individual betterment.

In his second article, Frederick (1986) addressed the crucial points not discussed by scholars of the CSR-1 era and provided enough evidence to support the view that scholars of the CSR-2 and CSR-3 era were responsible for introducing CSR as a strategical managerial tool.

\section{CSR-2: Early 1970s to Mid-1980s}

Frederick (1978) coined CSR's second evolutionary stage as CSR-2. Abernathy et al. (2017) maintained that scholars of the CSR-1 era focused on the development of the necessary tools to facilitate formal research and the expansion of concepts that could fill literature gaps. Freeman and Dmytriyev (2017) affirmed that researchers of the CSR-1 era tried to convince business leaders that engaging in CSR activities was the ethical and moral thing to do; however, the new wave of researchers and business professionals attempted to locate the necessary elements to engage in rewarding CSR activities. The need for a clear and concise definition of CSR was evident. Business leaders understood that there was a need for organizations to become socially responsible; however, no practical managerial tools had been addressed or introduced. Business leaders of the CSR-2 era struggled to find the answer to several fundamental questions:

\section{- How can organizations develop suitable CSR strategies?}

- What amount of resources should organizations allocate to the development and preservation of CSR programs? Is there a positive or negative relationship between
CSR strategies and financial performance?

Frederick (1986) mentioned that the CSR-2 period was viewed as CSR's most notable revolutionary phase. Frederick pointed out that researcher of the CSR-2 era evaluated concepts such as (a) financial performance, (b) social involvement, and (c) the newly introduced stakeholder theory. Kang and Liu (2015) advocated the view that researchers of this era began to recognize the numerous stakeholders, 
without obviating its primary goal, serving their communities through CSR programs and activities. Porter and Kramer (2007) concluded that the moment business professionals witnessed an attempt to measure CSR against financial performance was the moment business leaders began to accept the CSR theory as a strategical tool. Frederick (1986) clarified that researchers of the CSR-2 era rejected the notion that CSR was a trade-off between organizational leaders, and societies, and that there was a clear relationship between CSR and financial performance. Frederick also mentioned that within the CSR-2 period, an era of partnerships among business professionals of the same industries emerged. This macro approach materialized from the collaboration of leaders of multinational organizations who experienced ethical dilemmas on foreign soil and did not possess the ability or the financial capacity to resolve the ethical turmoil. According to Frynas and Yamahaki (2016), though researchers of the CSR1 era were perceived as CSR's introductory living organisms, business professionals and scholars of the CSR-2 epoch embraced the revenue-driven mentality and decided to research CSR as an executing mechanism. As mentioned by Ranängen (2016), researchers of the CSR-2 epoch decided to further develop an analytical approach to CSR. Harrison, Freeman, and Sá de Abreu (2015) argued that this development allowed researchers to demonstrate that a clear relationship between CSR and stakeholder theories (see Harrison et al., 2015). The proposed relationship between the CSR and the stakeholder theories served as the fueling apparatus to increase the momentum and the interest of scholars who once showed fascination in examining CSR strategies and its relationship with financial performance (see Freeman \& Dmytriyev, 2017). As explained by $\mathrm{Yu}$ and Choi (2016), scholars and professionals of the CSR-1 and CSR-2 era, introduced numerous revolutionary movements, but still experienced abundant shortcomings. Hategan, Sirghi, CureaPitorac, and Hategan (2016) argued that researchers of the CSR-2 period failed to (a) segregate CSR's ethical approach (b) to provide a model capable of measuring CSR (c) address the importance of adequately reporting CSR activities to stakeholders, and (d) clarify the vague concept of social betterment. Freeman and Dmytriyev (2017) commented that business professionals and scholars of the CSR-2 era failed to anticipate and mitigate the 1960's and late 1970's insertion of public awareness movements against businesses that profited from the exploitation of natural resources and human labor. Freeman and Dmytriyev emphasized that because practitioners of the upcoming CSR field did not develop strategies capable of combating the emerging social movements, lawmakers of the era were forced to increase the minimum wage and introduced multiple costly governmental directives that opened the doors of unionized employment movements. Brown and William (2013) argued that legislation was ultimately passed to calm the demands of a population that understood that organizations needed to be recognized as legitimate social citizens.

\section{CSR-3: 1980 to the Present}

Frederick (1978) understood that researchers of the CSR field became stagnant after its second evolutionary stage. Frederick (1986) mentioned that during the CSR-3 period, scholars defined the concept of CSR as the economic, legal, and ethical actions taken by organizational leaders in pursuit of social betterment, without compromising the organization's current financial state. The newly adopted definition covered the gaps initially neglected by researchers of the CSR-1 era, and subsequentially semi-covered by scholars of the CSR-2 epoch.
Kang, Germann, and Grewal (2016) pointed out that the definition presented by intellectuals of the CSR-3 period addressed the ethical, financial, and operational factors needed to gain credibility among business scholars and professionals. Yu and Choi (2016) argued that scholars of the CSR-3 era introduced a strategical operational approach designed to include and safeguard stakeholders such as (a) employees, (b) customers, (c) suppliers, (d) local communities, (e) government, and (f) international organizations. Recognizing that during the CSR-1 era business leaders were not capable of understanding the concept of CSR and that scholars of the CSR-2 period offered a vague understanding of CSR's core existence, academics of the CSR-3 era presented a revolutionary approach that postulated a clear understanding of the CSR concept from a strategical standpoint (see Frederick, 1986). Kang and Liu (2015) understood that researchers of the CSR-3 era focused on the development of ethical decision-making business leaders that could one day become capable of formulating socially-oriented strategies. Hsu and Cheng (2016) pointed out that the professional and academic literature presented by contemporary scholars offered a reactive solution to business leaders who tended to work towards the identification and the development of responsive measures that could alleviate any ethical or environmental dilemma. Smith and Colvin (2016) noted that business leaders and scholars tend to regularly address the benefits of openly reporting current and future CSR strategies to stakeholders. Leister and Maclachlan (2015) argued that business leaders of the CSR-3 period marked a pivotal point in CSR history, multinational executives and business leaders demanded the issuing of sustainability reports and decided to include their CSR actions in their letters to shareholders. Shareholders commenced to request supplementary CSR approaches, and organizational leaders understood that accomplishing or fulfilling those demands had a significant effect on market share value and future investments. Yang and Yao (2017) mentioned that an influential group of shareholders questioned current CSR reporting strategies and required the use of external CSR auditing firms. As a result, prominent CSR auditing firms and independent reporting tools such as (a) MSC KLD 400, (b) MSCI KLD, (c) Fortune Magazine Reputation Index, (d) Dow Jones Sustainability Index, (e) the Reputation Institute and (f) the Vigeo Index were introduced (see Kang \& Liu, 2015).

\subsection{The CSR Theory as a Planning Tool}

The concept of the CSR theory shifted the archaic valuemaximization model and introduced a notion that focused on the development of stakeholders such as individuals and communities. Practitioners of the CSR theory not only presented a different approach on how to conduct businesses but also streamlined the gap among stakeholders. Business leaders tend to portray shareholders as the sole stakeholders to be satisfied, obviating that revenue emerges from selling products or rendering services to a group of individuals that ultimately form a community. When building business models or setting objectives and projections, business leaders need to evaluate strategies capable of inducing social change or at least provide benefits to their employees. Though business practitioners accepted the CSR theory, several scholars and practitioners, such as Kim and Woo (2019), maintained that CSR strategies are implemented as a reactive mechanism to alleviate social pressure, which then translates to spontaneous and costly reactive measures. Given today's high levels of (a) cost management activities, (b) business intelligence evaluations, and (c) advanced analytical tools, business leaders can weigh the financial burden of engaging in CSR 
activities against the social cost of not doing so. While the CSR concept dates to the 1930s, its practice is viewed as a modern approach, an approach that business leaders can take to safeguard a role within their societies. It is evident that organizational culture and managerial expertise plays a vital role in the implementation of CSR strategies; however, Cantrell, Kyriazis, and Noble (2015) maintained that executives and business owners are required to lead adaptive organizations, adept enough to tackle the needs of their communities. Fontana (2018) sustained that practitioners of the CSR theory tend to understand that to maintain a good relationship with stakeholders, business leaders must create an organizational culture where stakeholders become familiar with the organization's mission, vision, and values. Though Frederick (1978) understood that an organization's financial situation limits its CSR engagement levels, Frederick (1986) maintained that the need for CSR strategies to be incorporated as an operational reality was needed. Organizational leaders experience or execute CSR in numerous ways (see Johnson, Ashoori, \& Lee, 2018). Cheng, Ioannou, and Serafeim (2014) established that executives and business leaders strive to attain different degrees of CSR involvement; however, Frederick (1978) argued that business leaders should avoid the hasty reaction to society's wishes at any cost. Frynas and Yamahaki (2016) mentioned that organizational leaders are required to formulate CSR scanning mechanisms capable of detecting social adversities at an early stage. Fanti and Buccella (2017) and Kang et al. (2016) mentioned that Frederick offered a model that could be considered a static strategical tool and was not designed to evaluate social changes after the implementation of suitable CSR strategies. While understanding that Frederick set the conditions for today's CSR engagements, Babiak and Kihl (2018) emphasized that Frederick failed to provide an operationally-oriented model capable of measuring and delivering quantifiable CSR information to leaders at all levels. Bridoux and Stoelhorst (2016) concluded that Frederick introduced the CSR theory as a moral principle that would justify the attempts and efforts made by business leaders that decided to invest in social betterment; the reason, in this quantitative correlational study a clear and concise strategical model that offer the necessary tools to allow organizational leaders to measure CSR reporting levels at any given time was provided. The importance of treating CSR reporting as a planning mechanism needs to be a topic of constant debate among business leaders.

\subsubsection{The Stakeholder Theory}

Pérez and Rodriguéz del Bosque (2016) presented arguments to emphasize that by introducing the stakeholder theory, Freeman (1984) (a) shaped the business world, (b) transformed the scholarly discussion of the stakeholder approach, and (c) established the foundation of today's business practice. Freeman suggested that the stakeholder terminology was first introduced during the 1960s; however, the stakeholder theory as a strategical approach emerged during the mid-1980s. Freeman (2010) indicated that the antiquated stakeholder approach limited the adaptation of organizational leaders, an action that prevented business leaders from reacting to the changes brought by the accelerated technological revolution. Brulhart, Gherra, and Quelin (2019) concluded that researchers in support of the newly introduced stakeholder approach embraced concepts such as ethics and business social responsibility. Miles (2017) argued that the inspiration behind the stakeholder approach was to build a framework capable of answering the concerns of organizational leaders that became stagnant due to the unprecedented changes in their business environments. Bridoux and Stoelhorst (2016) established that business leaders that followed traditional strategical approaches were not capable of developing deliberate business models, nor could they comprehend the opportunities that emerged from the uninterrupted business environments and social transformations. As indicated by Freeman (1984, 2010), stakeholder approaches introduced before the 1980s were inconsistent due to the number of disconnected theoretical frameworks presented by previous scholars, and the reactive nature that characterized them. Freeman (1984) identified the need for a new conceptual framework, one capable of addressing the challenges faced by business leaders of the era. Freeman introduced the refined stakeholder approach, and with it, the intention of expanding the concept of strategic management. Freeman presented the term by defining stakeholders as any group or individuals that can be affected or can affect an organization's financial objective. Yang and Bentley (2017) suggested that Freeman tried to devise a strategic methodology that would allow business leaders to assess the needs of a myriad group of stakeholders and its relationship with organizational performance. Kim (2017) confirmed that although the technological revolution of the 1980s facilitated the introduction of the stakeholder approach as a strategical tool, the idea was not utterly innovative. However, Freeman (1984) was the first scholar to indicate that business leaders needed to comprehend the interests of not only shareholders but also (a) employees, (b) customers, (c) suppliers, (d) lenders, and (e) societies. Jones, Harrison, and Felps (2018) mentioned that by analyzing the needs of stakeholders such as (a) employees, (b) customers, (c) suppliers, (d) lenders, and (e) societies, business leaders could develop business objectives and strategies capable of earning the support of key stakeholders. Weitzner and Deutsch (2019) pointed out that the stakeholder approach earned the respect of business professionals and scholars after Freeman decided to include strategical frameworks such as (a) corporate planning, (b) the system theory, (c) the organizational theory, and (d) corporate social responsibility. Freeman's newly introduced list of stakeholders gave the power to internal and external groups that were not traditionally addressed by business leaders (see Freeman \& Dmytriyev, 2017). Harrison et al. (2015) explained that the comprehensive view presented by Freeman $(1984,2010)$ seamlessly segregated stakeholders and assigned levels of importance to each group. Babiak and Kihl (2018) suggested that business strategies introduced before Freeman's broad definition of stakeholders offered business leaders a limited sense of corporate social responsibility. Guibert and Roloff (2017) pointed out that organizational leaders who understand the influence that groups of interest and entities have on their organization's overall performance are more likely to engage in productive, sustainable CSR practices. Brulhart et al. (2019) presented arguments to emphasize the view that organizational leaders need to demonstrate high levels of stakeholder awareness and include strategical approaches tailored to their organizational needs. Freeman and his stakeholder theory are targeted by constant criticism (see Miles, 2017). Freeman's attempt to balance the feedback received after the introduction of his stakeholder theory had created a sense of ambiguity. Weitzner and Deutsch (2019) mentioned that dividing the stakeholders into internal and external groups created a sense of difficulty. Yang and Bentley (2017) argued that stakeholders should be segmented by financial impact, not by an ethical or moral lens. Jones et al. (2018) maintained that not balancing the diverse stakeholders' interest, demonstrate a sense of ambiguity that can deviate organizational leaders from their 
original organizational mission and vision. Weitzner and Deutsch (2019) maintained that Freeman covered the importance of balancing the stakeholder's interest but failed to deliver a comprehensive answer on how business leaders could accomplish so. Ranängen (2016) argued that failing to determine the legitimacy of groups of interest, restricted the usefulness of the stakeholder theory. Guibert and Roloff (2017) observed that while providing a framework to segregate stakeholders, Freeman did not provide the tools to balance the needs of stockholders and stakeholders. Authors such as Bridoux and Stoelhorst (2016) concluded that Freeman's stakeholder theory continues to be criticized for a simple reason, it does not cover the issues that emerge when organizational leaders deal with situations where conflict of interest among stakeholders exists. Scholars such as Ranängen and Miles suggested that Freeman and supporters of the stakeholder theory needed to refocus the theory and converted it into a theory of shared responsibility among business leaders and stakeholders. Guibert and Roloff explained that Freeman's stakeholder approach does not cover the innate liability shared between stakeholders and business leaders, representing a critical limitation to the stakeholder theory. Brulhart et al. argued that scholars tend to address the responsibilities held by business leaders and stakeholders; however, minimal academic and professional literature can be found to addresses the opposite. Babiak and Kihl defended the notion that a sense of (a) reciprocity, (b) interdependence, and (c) accountability is essential to satisfy the relationship between businesses and stakeholders. Babiak and Kihl defined (a) reciprocity as the shared responsibility between stakeholders and businesses, (b) interdependence as the collective consequences emerged from organizational and stakeholder actions, and (c) accountability as the ability to hold each other accountable for their actions. Leister and Maclachlan (2015) believed that adding stakeholder's responsibility to Freeman's stakeholder theory delivers a distinguishable structure when discussing CSR from a managerial standpoint. Hsu and Cheng (2016) explained how the dual responsibility methodology could motivate business leaders and stakeholders to collaborate and support CSR initiatives. Following a similar rationale, Cohen, Holder, and Khalil (2017) attempted to convince business leaders and stakeholders, that an increase in stakeholder contribution can translate to enhanced CSR performance. CSR performance in relation to the stakeholder theory, equates to social betterment and that the obligation of improving our societies is a combined effort. Business leaders and stakeholders are fundamental parts of society; the reason, enough energy, and capital should be allocated to the betterment of their communities when financially permissible. By introducing the stakeholder theory, Freeman exemplified the notion of stakeholder management (see Freeman and Dmytriyev, 2017). By embracing the stakeholder management approach, Freeman and Dmytriyev established that (a) organizational leaders need to enhance their ability to categorize and distinguishing stakeholders, (b) business leaders need to determine the organizational impact of each stakeholder and (c) that organizational leaders need to create, nurture, maintain and cherish the professional relationship with stakeholders. Pérez and Rodriguéz del Bosque (2016) explained that when Freeman introduced the stakeholder theory, he intended to demonstrate that organizational leaders needed to address the interest of stakeholders at the time of making crucial business decisions. Freeman's strategical approach segregated the stakeholder theory from other managerial strategies, rendering a sense of uniqueness (see Agudo et al., 2015) while allowing business leaders to assign a direction to their CSR practices (Marples, 2017). Freeman's stakeholder theory is often associated with Frederick's CSR theory and approach.

\subsubsection{The Stakeholder Theory and its Relationship with CSR}

The traditional understanding of stakeholders did not offer the tools needed to address the rapidly changing business world. Freeman (2010) offered his gratitude and commented that scholars of his epoch expanded the definition of stakeholders, and introduced a larger group of interest that organizational leaders needed to attend to survive in today's volatile business environment. As an acceptance gesture, Freeman extended the definition of stakeholder and pointed out that stakeholders are individuals and entities that can be affected by any organizational actions (see Freeman, 2010). Freeman argued that individuals and organizations that can be affected by any organizational actions could be grouped among the following stakeholders (a) employees, (b) customers, (c) suppliers, (d) creditors, (e) communities, (f) governmental institutions, (g) political groups, and (h) competitors. After additional scrutiny, and seeking to address the received initial scholarly criticism, Freeman (2010) introduced the term key stakeholders and mentioned that organizations should focus on (a) customers, (b) employees, (c) investors, (d) suppliers, (e) communities, and (f) governments. Freeman continued to improve his stakeholder approach and later recognized the second wave of stakeholder, the external stakeholders (see Freeman \& Dmytriyev, 2017). Brown and William (2013) mentioned that after the introduction of external stakeholders such as, (a) consumer advocates, (b) preservationists, (c) groups of interests, and (d) nonprofit organizations, the same became relevant to business leaders. Freeman (2010) mentioned that the external stakeholders provided a new approach, and with it, the need for a new wave of organizational leaders capable of addressing their necessities. Though external stakeholders represent a crucial and pivotal element for today's business models, scholars such as Hategan et al. (2016) maintained that organizational leaders should solely focus on critical stakeholders because external stakeholders do not pose a threat to an organization's survival.

Scholars such as Jones et al. (2018) argued that supporters of the stakeholder theory tend to focus on value maximization, obviating any external factors or external stakeholders. Jones et al. also mentioned that the reality is that business leaders exist to provide shareholders with their expected return on investment. Harrison et al. (2015) argued that Freeman offered a framework that could be employed to analyze internal and external factors capable of inducing organizational change. Researchers and business professionals tend to post arguments to establish a clear connection between financial performance and proper stakeholder management. Business leaders must possess the aptitude to (a) segregate key stakeholders, (b) assess their needs, and (c) maintain an ethical relationship. Understanding that supporters of the stakeholder theory understood that Freeman's framework is an essential element of today's business environments, CSR scholars emphasized the need for attending not only the community but also the rest of stakeholders. Frynas and Yamahaki (2016) explained that the alignment of both theories reinforces the need for practical CSR strategies. Hetze (2016) argued that users of these strategies need to become capable of addressing not only stakeholders, such as employees but also their communities. Frynas and Yamahaki understood that satisfying a community while attending the social demands imposed by investors, and governmental 
agencies can become a harsh task. Jones et al. (2018) mentioned that business leaders who combine the stakeholder and the CSR theories become capable of evaluating key stakeholders and developing CSR strategies tailored to their necessities. Michelon et al. (2015) maintained that organizational leaders tend to face difficulties at the time of quantifying CSR implementation, or at the time of developing operationally compatible CSR strategies. Frynas and Yamahaki argued that by utilizing Freeman's stakeholder theory as a framework, business leaders could become capable of (a) assessing CSR performance, (b) gain stakeholder acceptance, and (c) increase the stakeholder's willingness to maintain the proposed CSR initiatives. Agudo et al. (2015) mentioned that contemporary theorists tend to relate to Frederick's work with Freeman's stakeholder theory. Freeman (2010) argued that business leaders could become capable of determining and addressing the necessities presented by stakeholders but struggle to segment their communities and discuss their current necessities. Freeman conveyed that communities play a vital role in an organization's lifespan and should not be precluded. Harrison et al. (2015) maintained that researchers could easily argue that the stakeholder theory is an integral aspect of the CSR theory. Jones et al. (2018) emphasized that supporters of the stakeholder theory tend to establish the need for developing business models that encompass the betterment of their communities, and the strong relationship between business leaders and stakeholders. Researchers such as Zhang and Zhang (2016) endorsed a more modern approach and advocated the view that CSR performance is associated with an organizational leaders' ability to identify groups of interest, as well as their proficiency at the time of developing appropriate CSR programs. Although trying to pinpoint the etymology of the word CSR can be a difficult task, Frynas and Yamahaki stated that aligning Freeman's stakeholder theory with Frederick's CSR approach facilitated their research process. When analyzing a significant amount of peerreviewed articles and books, attempting to assign a chronological line to CSR became a tedious assignment. Frederick's CSR theory and Freeman's stakeholder approach intertwine and can one day become a single methodology; however, this ideology cannot become a reality until scholars develop a CSR-quantifiable model.

\subsection{The Development of a Sustainable CSR Program}

CSR actions are the organizational efforts employed by business leaders capable of inducing social change. Business professionals that tend to embrace CSR are recognized as individuals seeking social betterment. However, the normative that CSR initiatives can positively benefit the financial performance of a company is a topic of constant debate among scholars and business professionals. Understanding that the employment of CSR is driven by significant economic developments such as globalization and sustainability, Kang et al. presented arguments to emphasize that organizational leaders must evaluate CSR at the time of developing or refining today's complex business models. Cheng et al. (2014) pointed out that CSR initiatives are an underestimated planning tool, and that it requires the same attention organizational leaders give to crucial strategical elements such as (a) price, (b) quality, and (c) demand. It is evident that transforming CSR from a reactive tool to a planning mechanism is essential to develop the CSR field even further (see Zhang \& Zhang, 2016). Brown and William (2013) presented arguments to advocate the view that scholars and CRS-practitioners need to present empiric data capable of demonstrating that CSR strategies can transcend and become more than an instrument applied to cushion scandals involving (a) labor abuse, (b) international labor rights, and (c) environmental exploitation. CSR consultants can provide an outside perspective of the problems experienced by the communities under scrutiny, allowing business leaders to determine a suitable organizational approach. Hsu and Cheng (2016) pointed out that business leaders attempting to develop valuable CSR programs need to assess the available CSR literature and seek for pertinent external validation. Smith and Colvin (2016) proposed that today's business practices call for not only environmentally sustainable approaches but also a business environment free of unethical behaviors. Organizational leaders belonging to the same industry tend to experience similar unfavorable circumstances. Harrison et al. (2015) understood that after analyzing the common ethical trends, and by embracing CSR strategies as a preventive mechanism, business leaders could mitigate the negative consequences associated with a previously assessed crisis. Smith and Colvin recognized that additional occurrences could pose a different set of difficulties, for which CSR preventing tools can serve as the cushion business leaders need at the time of tackling a crisis. Greater volume of academic literature would one day allow the CSR field to transcend and become a widely-renown and respected strategical instrument among business leaders. The managerial implementation of CSR strategies will one day become a requirement among business practitioners at all organizational levels.

\section{METHODOLOGY}

Bernard and Bernard (2017) mentioned that the formulation of a research question and hypothesis typically guides the selection of a research methodology. For the purpose of this study, we selected the quantitative method. The research question: "What is the relationship between CSR reporting, CSRi, and the financial performance of hardware and software organizations listed in the United States?" was designed to ignite curiosity among scholars and business practitioners that understand that a possible association between CSR reporting and financial performance exists. The independent variables were CSR reporting and CSRi. The dependent variables were NI and ROA. To confirm or deny the relationship between the independent and dependent variables, we (a) exported the sample's financial information, (b) CSR reporting values, and (c) CSRi information from Microsoft Excel to IBM SPSS version 26 and conducted a complete correlational analysis. Thanks to IBM SPSS userfriendly analytical platform, we were able to evaluate the following hypotheses:

H1。: There is no significant relationship between CSR reporting, CSRi, and the NI of hardware and software organizations listed in the United States.

$\mathrm{H} 1_{1}$ : There is a statistically significant relationship between CSR reporting, and the NI of hardware and software organizations listed in the United States.

$\mathrm{H} 2_{0}$ : There is no significant relationship between CSR reporting, CSRi, and the ROA of hardware and software organizations listed in the United States.

$\mathrm{H} 2{ }_{1}$ : There is a statistically significant relationship between CSR reporting, CSRi, and the ROA of hardware and software organizations listed in the United States.

The correlation values are interpreted as such (a) $r 2<.34$ is weak (b) $r 2$ between .35 and .60 is significant, and (c) $r 2>.61$ 
is strong. The information surrounding the dependent and independent variables were exported from Microsoft Excel to IBM SPSS. We organized the financial information surrounding the dependent variables NI, and ROA and the independent variables CSR reporting and CSRi into four different columns. The vertical placement of the variables facilitated the employment of IBM SPSS version 26 to test the assumptions of (a) multicollinearity, (b) outliers, (c) normality, (d) linearity, (e) homoscedasticity, and (f) independence of residuals. To quantify the data associated with the independent variable CSR reporting, we first used IBM SPSS Modeler Text Analytics version 18.0 to code the sample's annual reports as issued to the SEC between the years 2010-2015. After coding the annual reports, the results were augmented by a five-point Likert scale. Through the coding process, we attempted to locate criteria such as (a) environment (b) sustainability, (c) social responsibility, (d) employee development, (e) safe labor practices, and (f) charity. Besides the internet, Bloomfield et al. (2016) recommended the use of (a) physical and web-based libraries, (b) surveys, (c) observation logs, and (d) the employment of formal interviews. The sample's financial information was retrieved from (a) the sample's official web pages, (b) the SEC official web page, (c) macrotrends.net, (d) NASDAQ.com, and (e) reuters.com. The dependent variable ROA was re-calculated by appraising the sample's total assets between the years 2010-2015. This information was retrieved from the same web pages. The independent variable CSRi was extracted from the sample's consolidated Global CSR RepTrak scores as provided by the Reputation Institute. The Reputation Institute evaluates seven general dimensions (Fombrun, 2007). The Reputation Institute evaluates dimensions such as (a) products and services, (b) innovation, (c) workplace, (d) governance, (e) citizenship, (f) leadership, and $(\mathrm{g})$ financial performance. The dimensions constitute a score that ranges from 0-100. The sample's RepTrak scores for the years 2010-2015 were donated by the Reputation Institute to further enhance current CSR literature.

\section{SUMMARY OF THE FINDINGS}

The initial intention was to utilize the entirety of the software and hardware organizations that were part of Fortune 500 between the years 2010-2015 as the populationlsample. After applying industry filters such as (a) computer office equipment, (b) computer peripherals, (c) computer software, (d) information technology services, (e) electronic and office equipment, (f) network, and other communication equipment, (g) semiconductors, and $(\mathrm{h})$ other electronic components to the Fortune 500 lists between the years 2010-2015, a total of 51 organizations emerged. Out of the 51 hardware and software organizations, (a) three were acquired by larger corporations between the 2010-2015 period, (b) 13 were discarded due to a lack of CSRi information, and (c) 10 were identified as critical outliers. The sample was reduced to 25 . The critical outliers emerged from the organizations that showed significantly large NIs. After removing the NIs identified as outliers, the distribution of the data showed a relatively normal distribution, one that presented a skewness and kurtosis Z-value that was not less than -1.96 or greater than 1.96. Organizations with a ROA of $5 \%$ or higher are considered great investment opportunities. The statistical mean of the data surrounding ROA was $4.3 \%$, proving that the gathered information was suitable for this study. CSR reporting displayed a statistical mean of 1.4 , revealing low
CSR reporting values among the sample. CSRi, on the other hand, showed a moderate level of CSR by displaying a statistical mean of 67.4.

\section{Inferential Results}

For the purpose of this quantitative correlational study, we used a multiple linear regression model to examine the relationship between CSR reporting, CSRi, and the financial performance of 25 hardware and software organizations. The multiple linear regression analysis is typically used to determine the relationship between two independent variables and one dependent variable. The independent variables were CSR reporting and CSRi. The dependent variables were NI and ROA. The null hypothesis was that CSR reporting and CSRi were not significantly correlated with the financial performance of 25 hardware and software organizations. Following the recommendations of Poole and O'Farrell (1971), the occurrence of Type I and Type II errors were mitigated by testing the assumptions of (a) multicollinearity, (b) outliers, (c) normality, (d) linearity, (e) homoscedasticity, and (f) independence of residuals; no significant violations were encountered. A multiple linear regression model was used to statistically assess the independent variables CSR reporting, and CSRi against the dependent variable NI. The model showed a positive but weak relationship between the independent variables CSR reporting, CSRi and the dependent variable $\mathrm{NI}, F(2,22)=.389, p=.682, r 2=.03$. Since $p>.05$, the null hypothesis stating that there is no significant relationship between CSR reporting, CSRi, and NI was accepted. The $r 2$ value of .034 demonstrates that when measured against CSR reporting and CSRi, NI has no significant relationship. Utilizing the same multiple linear regression model, we attempted to obtain a significance level of $p \leq .05$ or an $r 2>.35$ to confirm or deny the relationship between the independent variables CSR reporting, CSRi, and the dependent variable ROA. The model showed a positive but weak relationship between CSR reporting, CSRi, and ROA, $F(2,22)=.552, p=.584, r 2=.048$. Since $p>.05$, the null hypothesis stating that there is no significant relationship between CSR reporting, CSRi, and ROA was accepted. The $r 2$ value of .034 demonstrated that when measured against CSR reporting and CSRi, ROA has no significant relationship.

\section{Analysis Summary}

The purpose of this quantitative correlational study was to confirm or deny the relationship between CSR reporting and financial performance. A multiple linear regression model demonstrated that implementing higher levels of CSR reporting does not necessarily equate to an increase or decrease in financial performance. To verify the validity of the chosen statistical model, we decided to test the assumptions of (a) multicollinearity, (b) outliers, (c) normality, (d) linearity, (e) homoscedasticity, and (f) independence of residuals. No major violations were encountered. The model showed that there was no significant relationship between the dependent variable NI and the independent variables CSR reporting, and CSRi, $F(2,22)=$ 
$.389, p=.682, r 2=.034$. The model also showed that the dependent variable ROA is not significantly correlated with the independent variables CSR reporting, and CSRi, $F(2,22)$ $=.552, p=.584, r 2=.048$.

\section{Theoretical Conversation on Findings}

Freeman's (1984) stakeholder and Frederick's (1978) CSR theories served as the theoretical framework for this study. As applied to this study, the stakeholder theory suggested that the independent variables CSR reporting, and CSRi drive financial performance. As applied to this study, the CSR theory suggested that a strong correlation between CSR reporting and financial performance existed. The statistical models did not support the notion that higher levels of CSR reporting translated to enhanced financial performance. Kang and Liu (2015) conducted a similar study and encountered an $r 2=.157$. Kang and Liu used the ratings provided by the Dow Jones Sustainability Group index and measured it against the dependent variables ROA and return on equity. Abernathy et al. (2017) recommended the use of CSR rating entities such as the KLD 400 as a key independent variable; however, Hetze (2016) utilized the KLD 400 ratings and proved that a negative relationship between CSR and financial performance existed $(r 2=-.001)$. The constant apparitions of weak but positive relationships between CSR and financial performance further enhance Brown and William's (2013) argument that organizational leaders and investors need to visualize CSR as a responsible act, not as an income-driven strategy.

\section{CONCLUSION}

Though limited empiric data exist to determine the impact CSR initiatives have on small- and medium-sized organizations, it is evident that shareholders continue to demand more CSR participation. The professional and academic literature that we used to shape this study helped to contribute to current CSR literature. We used two dependent variables to ignite critical thinking among professionals and scholars. Based on the encountered positive but insignificant relationship, it is safe to assume that if CSR-enthusiasts decide to evaluate additional variables to create a different statistical model, the model could reveal a higher level of correlation. Understanding that organizational actions need to be justified, in this study, we aimed to confirm or deny the relationship between CSR reporting, CSRi, and financial performance by employing a multiple linear regression model. The statistical models were designed to convey quantifiable data and to satisfy the value-maximation needs of the targeted audience. Small- and medium-sized organizational leaders could replicate this study by measuring CSR variables such as customer and employee satisfaction against dependent variables such as NI, and market share. Regardless of organizational size, NI, or social reputation, social responsibility is a collective obligation that requires a shared contribution.

\section{REFERENCES}

[1] Frynas, J. G., \& Yamahaki, C. (2016). Corporate social responsibility: Review and roadmap of theoretical perspectives. Business Ethics: A European Review, 25(3), 258-285. doi:10.1111/beer.12115

[2] Marples, R. (2017). Art, knowledge and moral understanding. Ethics and Education, 12(2), 243-258. doi:10.1080/17449642.2017.132342

[3] Svantesson, M., Silén, M., \& James, I. (2017). It's not all about moral reasoning: Understanding the content of moral case deliberation. Nursing Ethics, 25(2), 212-229. doi:10.1177/0969733017700235

[4] Agudo, V. J. M., Garcés, A. C., \& Salvador, F. M. (2015). Corporate social performance and stakeholder dialogue management. Corporate Social Responsibility \& Environmental Management, 22(1), 13-31. doi:10.1002/csr.1324

[5] Michelon, G, Pilonato, S., \& Ricceri, F. (2015). CSR reporting practices and the quality of disclosure: An empirical analysis. Critical Perspectives on Accounting, 33(3), 59-78. doi:10.1016/j.cpa.2014.10.003

[6] Babiak, K., \& Kihl, L. A. (2018). A case study of stakeholder dialogue in professional sport: An example of CSR engagement. Business \& Society Review, 123(1), 119-149. doi:10.1111/basr.12137

[7] Fontana, E. (2018). Corporate social responsibility as stakeholder engagement: Firm-NGO collaboration in Sweden. Corporate Social Responsibility \& Environmental Management, 25(4), 327-338. doi:10.1002/csr.1463

[8] Brown, J. A., \& William, F. R. (2013). CSR and stakeholder theory: A tale of Adam Smith. Journal of Business Ethics, 112(2), 301-312. doi:10.1007/s10551012-1251-4

[9] Frederick, W. C. (1978). From CSR1 to CSR2: The maturing of business-and-society thought. Business \& Society, 33(1), 150-164 doi:10.1177/000765039403300202

[10] Frederick, W. C. (1986). Toward CSR3: Why ethical analysis is indispensable and unavoidable in corporate affairs. California Management Review, 28(2), 126-142. doi: $10.2307 / 41165190$

[11] Abernathy, J., Stefaniak, C., Wilkins, A., \& Olson, J. (2017). Literature review and research opportunities on credibility of corporate social responsibility reporting. American Journal of Business, 32(1), 24-41. doi:10.1108/AJB-04-2016-0013

[12] Brown, H., \& Zmora, V. (2015). The role of corporate social responsibility (CSR) assurance in investors' judgments when managerial pay is explicitly tied to CSR performance. Auditing: A Journal of Practice \& Theory, 34(1), 75-96. doi:10.2308/ajpt-50813

[13] Freeman, R. E., \& Dmytriyev, S. (2017). Corporate social responsibility and stakeholder theory: Learning from each other. Emerging Issues in Management, 12(4), 7-15. doi:10.4468/2017.1.02

[14] Kang, H., \& Liu, S. (2015). Corporate social responsibility and corporate performance: A quantile regression approach. Quality and Quantity, 48(6), 311325. doi:10.1007/s11135-013.9958-6 
[15] Porter, M., \& Kramer, M. (2007). Strategy and society: The link between competitive advantage and corporate social responsibility. Strategic Direction, 23(5), 78-93. doi:10.1108/sd.2007.05623ead.006

[16] Ranängen, H. (2016). Stakeholder management theory meets CSR practice in Swedish mining. Mineral Economics, 30(1), 15-29. doi:10.1007/s13563-016-0098$\mathrm{z}$

[17] Harrison, J. S., Freeman, R. E., \& Sá de Abreu, M. C. (2015). Stakeholder theory as an ethical approach to effective management: Applying the theory to multiple contexts. Revista Brasileira de Gestão de Negócios, 17, 858-859. doi:10.7819/rbgn.v17i55.2647

[18] Yu, Y., \& Choi, Y. (2016). Stakeholder pressure and CSR adoption: The mediating role of organizational culture for Chinese companies. Social Science Journal, 53(2), 226-235. doi:10.1016/j.soscij.2014.07.006

[19] Hategan, C. D., Sirghi, N., Curea-Pitorac, R. I., \& Hategan, V. P. (2016). Doing well or doing good: The relationship between corporate social responsibility and profit in Romanian companies. Sustainability, 10(4), 127. doi:10.3390/su10041041

[20] Kang, C., Germann, F., \& Grewal, R. (2016). Washing away your sins: Corporate social responsibility, and firm performance. Journal of Marketing, 80(2), 59-79. doi:10.1509/jm.150324

[21] Hsu, J. L., \& Cheng, M. (2016). What prompts small and medium enterprises to engage in corporate social responsibility. Environmental Management, 19(5), 288305. doi:10.3215/151321-4

[22] Smith, K. J., \& Colvin, L. (2016). Creating and implementing codes of ethical conduct. Employment Relations Today, 43(1), 95-101. doi:10.1002/ert.21555

[23] Leister, D. V., \& Maclachlan, D. L. (2015). Organizational self-perception and environmental image measurement. Academy of Management Journal, 18(2), 205-223. doi:10.2307/25552

[24] Yang, C., \& Yao, L. (2017). Testing ambiguity theories with a mean-preserving design. Quantitative Economics, 8(1), 219-238. doi:10.3982/qe460

[25] Pérez, A., \& Rodriguéz del Bosque, I. (2016). The stakeholder management theory of CSR. International Journal of Bank Marketing, 34(5), 731-751. doi:10.1108/IJBM-04-2015-0052

[26] Kim, Y., \& Woo, C. W. (2019). The buffering effects of CSR reputation in times of product-harm crisis. Corporate Communications: An International Journal, 24(1), 21-43. doi:10.1108/ccij-02-2018-0024

[27] Cantrell, J., Kyriazis, E., \& Noble, G. (2015). Developing CSR giving as a dynamic capability for salient stakeholder management. Journal of Business Ethics, 130(2), 403-421. doi:10.1007/s10551-014-2229-1

[28] Johnson, Z., Ashoori, M. T., \& Lee, Y. J. (2018). Selfreporting CSR activities: When your company harms, do you self-disclose? Corporate Reputation Review, 21(4), 153-164. doi:10.1057/s41299-018-0051-x

[29] Cheng, B., Ioannou, I., \& Serafeim, G. (2014). Corporate social responsibility and access to finance. Strategic Management Journal, 35(1), 1-23. doi:10.1002/smj.2131
[30] Fanti, L., \& Buccella, D. (2017). Profit raising entry effects in network industries with corporate social responsibility. Economics and Business Letters, 6(3), 5967. doi:10.17811/ebl.6.3.2017.59-68

[31] Bridoux, F., \& Stoelhorst, J. W. (2016). Stakeholder relationships and social welfare: A behavioral theory of contributions to joint value creation. Academy of Management Review, 41(2), 229-251. doi:10.5465/amr.2013.0475

[32] Freeman, R. E. (1984). Strategic management: A stakeholder approach. Boston: Pitman.

[33] Freeman, R. E. (2010). Strategic management: A stakeholder approach. New York, NY: Cambridge University Press.

[34] Brulhart, F., Gherra, S., \& Quelin, B. V. (2019). Do stakeholder orientation and environmental proactivity impact firm profitability? Journal of Business Ethics, 158(1), 25-46. doi:10.1007/s10551-017-3732-y

[35] Miles, S. (2017). Stakeholder theory classification: A theoretical and empirical evaluation of definitions. Journal of Business Ethics, 142(3), 437-459. doi:10.1007/s10551-015-2741-y

[36] Yang, A., \& Bentley, J. (2017). A balance theory approach to stakeholder network and apology strategy. Public Relations Review, 43(2), 267-277. doi:10.1016/j.pubrev.2017.02.012

[37] Kim, Y. (2017). A qualitative research on the organizing and institutionalizing processes of social venture entrepreneurship. The Korea Entrepreneurship Society, 12(5), 19-43. doi:10.24878/tkes.2017.12.5.019

[38] Jones, T. M., Harrison, J. S., \& Felps, W. (2018). How applying the instrumental stakeholder theory can provide sustainable competitive advantage. Academy of Management Review, 43(3), 371-391. doi:10.5465/amr.2016.0111

[39] Weitzner, D., \& Deutsch, Y. (2019). Why the time has come to retire instrumental stakeholder theory. Academy of Management Review, 44(3), 694-698. doi:10.5465/amr.2018.0342

[40] Guibert, L., \& Roloff, J. (2017). Stakeholder dialogue: strategic tool or wasted words? Journal of Business Strategy, 38(5), 3-11. doi:10.1108/JBS-07-2016-0071

[41] Cohen, J., Holder, L., \& Khalil, S. (2017). A further examination of the impact of corporate social responsibility and governance on investment decisions. Journal of Business Ethics, 146(1), 203-218. doi:10.1007/s10551-015-2933-5

[42] Hetze, K. (2016). Effects on the (CSR) reputation: CSR reporting discussed in the light of signaling and stakeholder perception theories. Corporate Reputation Review, 19(3), 281-296. doi:10.1057/s41299-016-0002-3

[43] Zhang, H., \& Zhang, M. (2016). The corporate social entrepreneur: From concept to practice. Global Business \& Organizational Excellence, 35(2), 50-59. doi:10.1002/joe.21655

[44] Fombrun, C. J. (2007). List of lists: A compilation of international corporate reputation ratings. Corporate Reputation Review, 10(2), 144-153. doi:10.1057/palgrave.crr.1550047

[45] Poole, M. A., \& O'Farrell, P. N. (1971). The assumptions of the linear regression model. Transactions 
International Journal of Computer Applications Technology and Research Volume 9-Issue 04, 155-164, 2020, ISSN:-2319-8656

of the Institute of British Geographers, 145-158.

doi:10.2307/621706 